\title{
Desarticulando la guerra y el patriarcado, una propuesta museográfica de Medellín - Colombia*
}

\author{
Ana María Sosa** \\ Daniel Arias***
}

\begin{abstract}
Resumen
El presente artículo muestra como el Museo Casa de la Memoria de Medellín ha incluido la perspectiva de género dentro de su trabajo, a través del proyecto "Género, Memoria y Despatriarcalización", ejecutado entre 2014 y 2015. El mismo, partió de una propuesta de investigación-acción-participativa, que resultó innovadora, pues exploró la forma en que algunas configuraciones de género masculinas se vincularon con acciones violentas y con el conflicto armado colombiano. Se analizó cómo se formuló e implementó este proyecto, resaltando la lectura de la categoría "género" que hizo el equipo administrativo del museo, y que contempló la vinculación de varones como seres sexuados en la desarticulación del conflicto armado colombiano como una propuesta museográfica, evidenciando los principales impactos que tuvo este proceso.
\end{abstract}

Palabras clave: Despatriarcalizar, Género, Conflicto Armado, Políticas de Memoria de Colombia.

* Recibido el 02 de diciembre de 2017, aceptado el 24 de septiembre de 2020.

** Profesora Visitante extranjera en el Programa de Pós-Graduação em História de la Universidade Federal de Pelotas, Pelotas, RS, Brasil. Profesora de Historia por el Instituto de Profesores "Artigas" - IPA-, Uruguai. anasosagonzalez@gmail.com / http://orcid.org/0000-0001-7249-4618

*** Doctorando en Historia por el Centros de Investigaciones y Estudios Superios em Antropología Social en Mérida- México. Magíster en Políticas Públicas y Género Flacso Uruguay en convenio con Flacso México. Graduado en Historia por la Universidad Nacional de Colombia. Sede Medellín. daniel.arias70@gmail.com / https://orcid.org/0000-0003-0635-9324 
Disrupting War and Patriarchy, a Museological Proposal in Medellin - Colombia

\begin{abstract}
This article shows how The House of Memory Museum of Medellin has included gender perspective in its work, by examining the project "Gender, Memory and Depatriarchalization", implemented by the institution in 2014 and 2015. The project began from a participative action research proposal, which was innovative for exploring how some masculine gender configurations were linked to violent actions and the Colombian armed conflict. The purpose of this article is to analyze how the project was formulated and implemented, highlighting the reading of the category "gender" made by the museum's staff, and how the bonding of men as sexed beings in the disarticulation of the Colombian armed conflict was considered as a museological project.
\end{abstract}

Keywords: Depatriarchalizing, Gender, Armed Conflict, Policies of Memory in Colombia. 


\section{Introduccíon}

El conflicto bélico en Colombia ha tenido una gran envergadura y relevancia en los últimos setenta años de historia del país. Según el Registro Único de Víctimas del gobierno colombiano al 29 de julio de 2020, se contabilizan 9.031.048 víctimas, de las cuales 7.299 .457 son objeto de reparación ${ }^{1}$. Esto lo ha consolidado como uno de los problemas sociales de mayor gravedad en el país.

Las dinámicas de este conflicto armado, han variado significativamente, según la región del país (Pizarro, 2015. Este artículo se concentra en analizar la experiencia de Medellín, capital del departamento de Antioquia ${ }^{2}$. Tanto la ciudad como la región han sido reconocidas nacional $e$ internacionalmente por sus altos niveles de conflicto, lo que también ha contribuido a consolidar variadas experiencias de resistencia y memoria que resultan significativas (Centro Nacional de Memoria Histórica, 2017b).

De acuerdo con el informe: "Medellín: memorias de una guerra urbana", realizado por el Centro Nacional de Memoria Histórica en 2017, 6 de cada 100 personas fueron víctimas del conflicto o estuvieron afectadas por él, entre los años 1980 y 2014. Este documento precisó que la expansión de los grupos paramilitares y las guerrillas rurales convirtió a la ciudad en el principal territorio de conflicto del país entre 1995 y el 2005. Subrayó que los actores armados que tuvieron presencia en la ciudad, recurrieron a una gran variedad de violencias, como el desplazamiento forzado, asesinatos selectivos, masacres, secuestros, reclutamientos de niñas/os o violencia sexual, prácticas

\footnotetext{
1 Durante el conflicto armado colombiano han existido diversas formas de violación a los Derechos Humanos, por eso las cantidades son tan exorbitantes, pues el conflicto se ha librado de muchas maneras, desde minas antipersonales hasta masacres y violaciones a mujeres. Para ver actualizado el número de víctimas en Colombia [https://www.unidadvictimas.gov.co/es/registro-unico-devictimas-ruv/37394. Acceso: 11 de noviembre de 2020]

${ }^{2}$ Departamento es el nombre para demarcar la división política administrativa de Colombia. Medellín es la capital del departamento de Antioquia.
} 
que se desarrollaron con diversos objetivos y tuvieron dimensiones variadas. Sostiene además, que el narcotráfico fue un actor relevante en el conflicto, pues logró inmiscuirse en las estructuras del Estado y en los grupos paramilitares y de guerrillas (Centro Nacional de Memoria Histórica, 2017b).

Ahora bien, en el año 2011 el Gobierno Nacional promulgó la Ley Estatal de Víctimas como una apuesta a la justicia, la verdad y la reparación a las víctimas de la guerra. Son varias las intervenciones que se han realizado en el marco de esta Ley, especialmente proyectos vinculados con la restitución de tierras, acciones afirmativas para generar acceso a servicios básicos de salud, educación, vivienda, etc. Otro de los compromisos asumidos por medio de esa ley han sido las reparaciones simbólicas, especialmente lo que respecta a la reconstrucción histórica de las memorias del conflicto.

Desde una perspectiva de género la mayoría de intervenciones se han focalizado en el universo femenino con el fin de promover reivindicaciones para grupos de mujeres (Viveros, 2002). Entre los proyectos a nivel nacional se destacan el plan nacional de prevención de riesgos y vulneraciones de las mujeres ejecutado durante los años 2013-2015 y el proyecto vivienda gratis destinado a hogares cuyas jefes de familia son mujeres víctimas del conflicto armado ${ }^{3}$. Además, se han ido incrementando las intervenciones que desde una concepción más amplia de género, abarquen otras identidades sexo-genéricas como poblaciones Lesbianas, Gays, Bisexuales, Transgeneristas, Intersexuales$\mathrm{LGBTBI}^{4}$ - y varones, también involucrados en el conflicto armado.

El Centro Nacional de Memoria Histórica ha sido pionero al mostrar cómo durante el conflicto armado, los diferentes grupos bélicos que han participado en este proceso, incluyendo al Estado,

\footnotetext{
${ }^{3}$ Información extraída del artículo de prensa publicado el 26 de noviembre de 2013 "Programa para mujeres víctimas del conflicto armado tendrá $\$ 2,1$ billones" [https://www.elespectador.com/noticias/nacional/programa-paramujeres-victimas-del-conflicto-armado-tendra-2-1-billones-460628/ -acceso: 11 noviembre 2020]

${ }^{4}$ De aquí en adelante se nombrará por la sigla LGTBI.
} 
han establecido un orden moral basado en unas sexualidades $e$ identidades de género heteronormativas. Desde diversas publicaciones, los informes presentados por esta institución han enunciado que:

La guerra ha formado una llave con el sistema sexo/género tradicional de la sociedad colombiana, contribuyendo a formar subjetividades masculinas guerreras y subjetividades femeninas cosificadas, las cuales componen dos polos de la distribución de poderes [...] Las armas y el poder que generan los uniformes se convierten en unas de las pocas posibilidades de obtención de capital simbólico con la que cuentan muchos hombres ubicados en posiciones sociales, económicas y territoriales marginadas. La figura del guerrero no apareció espontáneamente en el escenario social del país, esta ha sido el producto de continuos procesos de socialización de género donde los niños son preparados para encarnar la figura del "héroe de la patria", del paramilitar o del rebelde (Centro Nacional de Memoria Histórica, 2017a:156-157)

El informe "La guerra inscrita en el cuerpo", además de recopilar los testimonios de víctimas de violencia sexual, retoma las investigaciones de Camila Medina Arbeláez (2008) y de Darío Muñoz-Onofre (2011), para proponer que, en el conflicto armado hubo unos patrones de socialización que configuraron un orden de género jerárquico y que hicieron proclive la participación de los hombres en la guerra. El informe a su vez, retoma algunas de las ideas centrales de Medina (2008) para reafirmar que la configuración de unas masculinidades bélicas se ha forjado en cuatro pilares. El primero está vinculado con la legitimación de una doctrina militar, que se basa en la ordenación de unas relaciones de poder (generales, jefes, oficiales y tropa). El segundo, está basado en las prácticas de adoctrinamiento corporal y psicológico para participar de los enfrentamientos militares. El tercer en la expulsión de todo aquello que pudiere ser calificado como femenino (debilidad, formas de hablar, etc.). Y, por último, 
las relaciones de jerarquía que se construyen con la población civil. También observa el lugar que esos hombres que han participado del conflicto armado han utilizado, para demarcar ejercicios de violencia contra las mujeres, y hostigar a aquellos hombres que han configurado otras masculinidades, como hombres identificados como homosexuales (Centro Nacional de Memoria Histórica, 2017a).

El Centro Nacional de Memoria Histórica también ha ahondado sobre las implicaciones que ha tenido ese orden de género, con aquella población que ha expresado sus orientaciones sexuales e identidades de género por fuera de la heteronormatividad. El libro "Aniquilar la diferencia, lesbianas, gays, bisexuales y transgeneristas en el marco del conflicto armado colombiano", adelantó los primeros pasos en mostrar como este orden de género sostuvo determinados ejercicios de violencia. Este informe ha precisado también, que los diversos grupos armados, exacerbaron unas diferencias entre masculino/femenino, dejando más expuestas/es/os a aquellas/es/os que no lograron hacer parte de este binomio (Centro Nacional de Memoria Histórica, 2015). Asimismo demarca que no todas las personas con identidades y sexualidades de género no hegemónicas fueron receptoras de violencia, sino aquellas que fueron visibles a los actores armados, ya sea porque se distanciaban sustancialmente del orden de género heteronormativo a través de sus expresiones/comportamientos; por querer vivir de manera pública sus sexualidades y afectos no normativos; o por su accionar político y comunitario, en el constante reclamo de sus derechos como sujetes con identidades y sexualidades no hegemónicas (Centro Nacional de Memoria Histórica, 2015).

Según el artículo "Hombres sin memoria" de Ana Cristina Restrepo, el $89 \%$ de los victimarios son hombres, incluyendo tanto a los varones que pertenecen a instituciones como los que operan al margen de ellas ${ }^{5}$, teniendo como característica común su

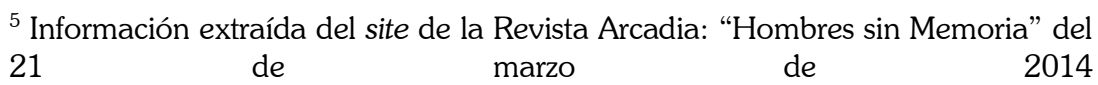


situación socioeconómica, pues en concordancia con el primer informe presentado por el Museo Casa de la Memoria son varones provenientes de ambientes precarios y violentos (Ossa, 2015).

De acuerdo con la publicación de febrero de 2014, de la Agencia Colombiana para la Reintegración - ACR- de las/os combatientes, las masculinidades que se construyen en contextos de guerra tienen ciertas particularidades, el ideal militar fomenta valores sobre lo que debería ser la dignidad humana, la división sexual del trabajo se acentúa entre hombres que van al combate y las mujeres que se encargan del cuidado en los hogares ${ }^{6}$. Ellos inhiben expresiones de tristeza, dolor y llanto, pues simbolizan debilidad, característica vinculada a la feminidad, y ellas desde su condición de género sufren violencias sexuales, intrafamiliares, entre otras tantas violencias simbólicas y físicas.

Todos los informes del Centro Nacional de Memoria Histórica, han recalcado que el sistema sexo/género imperante en el marco del conflicto armado ha demarcado un lugar para los hombres, ya fuere por sus políticas de reclutamiento, como el servicio militar obligatorio para hombres, en el aprendizaje de una educación para el combate, en la configuración de lugar de prestigio masculino basado en el uso de la fuerza bélica o, en los ejercicios de marginación de hombres que por medio de las armas demuestran su masculinidad en la burla y el hostigamiento hacia otros (sobre este punto, aún no hay un informe específico y los proyectos sustentados en esta idea, aún son incipientes).

En este contexto, El Museo Casa de la Memoria desarrolló un programa designado Género, Memoria y Despatriarcalización, cuyo propósito fue reflexionar y discutir alrededor de las diversas y

[http://www.revistaarcadia.com/impresa/reportaje/articulo/hombres-sinmemoria/36104 - acceso: 11 noviembre 2020].

${ }^{6}$ Información extraída del Informe de la Perspectiva de Género de la Agencia Colombiana para la Reintegración [https:/www.reincorporacion.gov.co/es/lareintegracion/centro-dedocumentacion/Documentos/Perspectiva\%20de\%20g\%C3\%A9nero\%20en\%20el \%20Proceso\%20de\%20Reintegraci\%C3\%B3n.pdf - Acceso: 23 octubre de 2016]. 
complejas relaciones entre género, conflicto armado, memoria y resistencias no violentas. Entre noviembre de 2014 y marzo de 2015 se llevó a cabo la fase inicial de esta iniciativa que bajo la metodología investigación-acción-transformador, denominada "Patriarcado, masculinidades hegemónicas y violencias: exploración en torno a la construcción de identidades masculinas que perpetúan los ciclos de violencia en Medellín, Colombia", desarrolló actividades tales como tertulias, talleres, etc., involucró 125 hombres y 36 mujeres de la ciudad de Medellín, y trabajaron alrededor de temas como el heroísmo, las imágenes cotidianas del guerrero, los mecanismos de socialización masculina, los rituales urbanos de masculinidad, entre otros tópicos que sirvieron de base para la segunda fase del proyecto, llamado "Hombres en construcción", el cual se ejecutó durante el segundo semestre del 2015, en la cual participaron 148 hombres y 16 mujeres, entre ellas una mujer transgénero.

El programa Género, Memoria y Despatriarcalización, que se ejecutó en la administración de la arquitecta Lucía González, fue innovador al poner en marcha una lectura de género que no es la convencional, donde se trabajó con varones y mujeres deconstruyendo posiciones de género hegemónicas, entendiendo el perjuicio del patriarcado, reconociendo el carácter histórico y social de la construcción de masculinidades hegemónicas bélicas, con el objetivo de transformar estos patrones de opresión y muerte relacionados de una manera muy estrecha con la guerra. Contribuyendo con ello a la deconstrucción de ese sistema y fortaleciendo identidades masculinas proclives a la vida (Museo Casa de La Memoria, 2015).

\section{Una ciudad que piensa en clave de masculinidades}

A partir de los diferentes informes presentados por el Centro Nacional de Memoria Histórica, es evidente la existencia de un problema público, el conflicto armado, que ha estado ligado a la configuración de unas masculinidades bélicas, que han hecho proclive la participación de los hombres en la guerra. Sumado a 
esto, la experiencia acumulada de la ciudad, que desde el año 2000 ha venido adelantando diversos trabajos con hombres en la deconstrucción de masculinidades, en asuntos relacionados con la participación de los hombres en las tareas del hogar, como en el cuidado de sus hijas/es/os, o en la prevención de violencias de género, permitieron el surgimiento de un proyecto que estudiara y contribuyera en la desarticulación de masculinidades hegemónicas bélicas.

El Centro Interdisciplinario de Estudios en Género de la Universidad de Antioquia fue el espacio que emprendió las primeras reflexiones sobre este asunto en Medellín, con la creación del grupo de investigación Construcción de Identidades Masculinas -CIMAS-, en el 2000, año en el que también se realizó el primer Encuentro de Masculinidades en la ciudad, que logró convocar a activistas y académicos a nivel nacional (García, 2013). A partir de ese momento, un grupo de profesionales ha venido trabajando la temática desde la academia y el activismo, donde ha sido muy relevante su actuación con diversos varones en la deconstrucción de prácticas masculinas, a través de talleres, tertulias, diplomados y conferencias. En una de las entrevistas realizadas se señalaron algunos de los principales investigadores que continúan trabajando el tema,

[...] [En] la reflexión de la academia entonces está Hernando Muñoz, el profesor que ahora es decano de la Facultad de Ciencias Sociales. Él hizo su tesis doctoral sobre masculinidades y Hernando ha sido además un activista. Un activista como en el campo de la flexibilización de los roles y de unas maneras de vivir como la identidad sexual menos constrictora [...] también Aníbal Parra. Aníbal fue director del Centro Interdisciplinario de Estudios de Género de la Universidad de Antioquia, también un hombre inquieto con ese tema de las masculinidades. Creo que también hizo una tesis, su tesis de pregrado [...] sobre el tema (Londoño, 2016). 
Teniendo este marco de referencia, y motivados por la directora del Museo Casa de la Memoria, esta institución construyó un proyecto sobre masculinidades. Las reflexiones previas sobre cuál es la situación en la ciudad con respecto a las construcciones de género que atañen a masculinidades hegemónicas y cuáles son los efectos que tienen estas prácticas tanto en la vida de los varones como en la sociedad en general resultaron determinantes en la formulación del proyecto:

\begin{abstract}
[...] tengo tres experiencias, marcas muy fuertes que me conducen al tema de lo masculino: uno, la experiencia familiar y social cercana donde ve uno reeditar sistemáticamente ese proyecto patriarcal hegemónico sobre todo por parte de las mujeres. Son las mujeres las que reeditan ese proyecto patriarcal hegemónico que les hace tanto daño después. Pero es así y es un proyecto imuy costoso! para la sociedad [...] Lo segundo es mi experiencia social. Mi experiencia social me pone en evidencia dos cosas, una: que no hay una reflexión sobre el proyecto masculino, que los hombres son los que más cerquita están del riesgo. De todos los riesgos, del riesgo de la droga, del riesgo de la delincuencia, del riesgo de la guerra. De participar en la guerra o porque sean soldados de esos ejércitos nacionales o porque sean miembros de las bandas criminales o de los grupos al margen de la ley y frente a eso veo que no hay ninguna reflexión. Lo otro es que participo del proyecto de reconstrucción del eje cafetero y muy rápido me doy cuenta que el enfoque privilegiado de género hacia las mujeres se convierte en un problema muy grave para atender situaciones integrales como las de las vulnerabilidades de esas comunidades después de una tragedia (González, 2016).
\end{abstract}

Gran parte del equipo que se encargó de la formulación y ejecución del proyecto son psicólogas/os de profesión, con experiencias previas en asuntos de masculinidades, varios de ellos que ya habían realizado varias intervenciones con varones de la ciudad, pues desde la Secretaría de las Mujeres de la Alcaldía de 
Medellín se venían generando acciones encaminadas a deconstruir prácticas masculinas hegemónicas desde el año 2010.

\section{Identificando un problema, pensando un objetivo en común}

Una de las reflexiones que tuvo mayor trascendencia al momento de formular el proyecto fue la relación que existe entre la construcción de masculinidades y la educación de los varones para la guerra. A partir de ahí, elaboraron una serie de reflexiones con varones de diferentes procedencias con el objetivo de sensibilizarlos sobre su participación en la guerra,

\section{[...] el objetivo que pretendíamos era que a través de la conversación....acercar a los hombres al deseo a la intención de desinstalar de sí, digamos: sacarse de la cabecita ese chip que predispone o pone al hombre en función de la violencia y de la participación en grupos armados. Digamos entonces que era como el objetivo fundamental. Aportar a eso y sobre todo generando también unos insumos de investigación que permitieran entonces hacer lecturas, formular artículos de diferentes aspectos que permitieran ilustrar allí cómo es ese asunto del hombre que le dice no a la guerra o del hombre que estuvo ahí cómo vivió eso (Osorio, 2016).}

Generar un espacio de reflexión sobre cuáles eran los insumos que los varones habían puesto para la guerra fue uno de los principales objetivos del proyecto, pues en sus reflexiones también habían identificado que uno de los pilares de las masculinidades en el país estaba dado por una educación para la guerra. En la documentación y material de trabajo que manejó el Museo para la formulación de este proyecto se encontró este aparte en el que se afirma,

No se nace guerrero, se llega a serlo, esto en la medida que la construcción de la masculinidad se fomentan unos compartimientos, se reprimen otros, siendo incluso la masculinidad militarizada algo mediado por los discursos $e$ 
intereses sociales que prefiguran y dan contenido a dicha construcción social de masculinidad. El moldeamiento social es un asunto del que no escapan las mujeres, pero tampoco los hombres (Osorio, 2014:6).

La identificación de este problema acompañado de otros factores relacionados con la construcción de masculinidades hegemónicas en la ciudad y los pocos espacios para la conversación con varones sobre cómo estas construcciones de género han impartido unas características en sus vidas, y cómo la cultura ha moldeado estos atributos, también con la finalidad de resaltar la labor de aquellos varones que día a día hacen resistencias a esos establecimientos culturales, hizo que el Museo diseñara un espacio para la conversación y la deconstrucción de prácticas masculinas hegemónicas que son nocivas para la sociedad.

\begin{abstract}
Entonces la idea desde el museo Casa de la Memoria era más abrir una reflexión que le sirviera a la sociedad, particularmente a la sociedad paisa [Antioquia]... que esos chicos tuvieran unos lugares de reflexión sobre eso y cómo lográbamos construir también unos líderes y unos maestros que acompañaran a los hombres en una pregunta por su sensibilidad por su desarrollo más integral por menos castración de sus posibilidades y de su lado femenino y al mismo tiempo pues, evitar que fueran violadores o esas cosas horribles que los hombres resolvieron ser en la vida (González, 2016).
\end{abstract}

Este proyecto logró identificar la manera en que los hombres en sus construcciones de género generan prácticas violentas nocivas para la sociedad y para ellos mismos, lo que en cierta manera ubicó a las/os profesionales bajo un problema en común y con un objetivo también compartido: desarticular ciertas prácticas masculinas hegemónicas de violencias, generando espacios donde se dialoguen estos temas entre varones, pues estas mismas 
construcciones de género no han permitido producir lugares para su enunciación.

Esta iniciativa se propuso trabajar con la mayor diversidad de hombres posibles. Tanto en su primera fase en el año 2014, como en su segundo año de funcionamiento, conformo grupos que fueron disímiles en sus lugares de procedencia, y sus configuraciones de género. En el siguiente cuadro se muestran los grupos que fueron construidos durante el 2014 (recordando que participaron 125 hombres y 36 mujeres):

Cuadro 1: Conformación de los grupos conformados entre Noviembre de 2014 y marzo de 2015

\begin{tabular}{|l|l|}
\hline $\begin{array}{l}\text { Amañadero de } \\
\text { Manes }\end{array}$ & $\begin{array}{l}\text { Hombres y algunas mujeres de edades diversas que } \\
\text { llegan al grupo por invitación voz a voz y con algún } \\
\text { grado de sensibilización respecto al tema }\end{array}$ \\
\hline $\begin{array}{l}\text { Hombres y } \\
\text { mujeres LGTBI }\end{array}$ & $\begin{array}{l}\text { Convocadas/os en alianza con el centro de diversidad } \\
\text { sexual y de género que opera en el sector de Villa } \\
\text { Nueva de la ciudad. }\end{array}$ \\
\hline $\begin{array}{l}\text { Hogar de } \\
\text { acogida de } \\
\text { Prado Centro }\end{array}$ & $\begin{array}{l}\text { Hombres y mujeres en situación de calle que se } \\
\text { encontraban para ese momento en una tapa } \\
\text { avanzada de su proceso de rehabilitación. }\end{array}$ \\
\hline $\begin{array}{l}\text { Soldados } \\
\text { discapacitados }\end{array}$ & $\begin{array}{l}\text { Soldados con alguna discapacidad física debido a la } \\
\text { prestación de sus labores como militares que estaban } \\
\text { en el programa del Escuadrón de Sanidad en la } \\
\text { Cuarta Brigada }\end{array}$ \\
\hline Comuna 8 & $\begin{array}{l}\text { Hombres líderes de la comuna 8 pertenecientes a } \\
\text { juntas de acción comunal }\end{array}$ \\
\hline Indígenas & $\begin{array}{l}\text { Hombres y mujeres indígenas asistentes permanentes } \\
\text { o esporádicos al Cabildo Indígena Chibcariwak }\end{array}$ \\
\hline $\begin{array}{l}\text { Colegio San } \\
\text { Ignacio }\end{array}$ & $\begin{array}{l}\text { Estudiantes de grado 117 convocados en convenio } \\
\text { con la institución educativa, con especial interés en } \\
\text { los temas de masculinidades y violencia }\end{array}$ \\
\hline
\end{tabular}

Fonte: Cuadro armado por Daniel Arias Osorio en base a la información extraída de la entrevista a la ex-Directora del Área de Investigación del Museo, Luz María Londoño (2016) y a la documentación publicada por el Museo sobre esa primera fase.

${ }^{7}$ Último grado en la educación secundaria colombiana. 
Algunos de los grupos que habían sido conformados durante este primer año continuaron en la segunda fase, los cuales fueron: el amañadero de manes, varones y mujeres LGBTI, hogar de acogida en Prado Centro y estudiantes del Colegio San Ignacio. Para el año 2015 se integraron dos nuevos grupos: uno de varones, convocados por la Junta de Acción Comunal del barrio Robledo Aures y; otro de mecánicos del barrio la Iguaná, agrupados por líderes del territorio. ${ }^{8}$ En esta segunda etapa se involucraron 148 hombres y 16 mujeres.

Bajo esta gran diversidad de población, mayoritariamente masculina, el grupo de profesionales a cargo del proyecto, decidió trabajar bajo la metodología investigación-acción participativa. Esta, según las precisiones de Colmenares, permite trabajar en dos procesos simultáneamente: conocer y actuar; de un lado propicia en las/os participantes reflexiones sobre el contexto en el que viven, al igual que las/os hace conscientes de las limitaciones, recursos y necesidades que tienen en sus comunidades; por otra parte, el conocimiento que adquieren de esas realidades les permite ser propositivos en las posibles soluciones, mejoras y transformaciones de los ítems que consideren deben cambiar (Colmenares, 2011). Bajo esta metodología los roles de facilitador/a y estudiantes se desdibuja y todas/os desde sus experiencias de vida comparten sus saberes, a partir de estos se generan nuevos conocimientos y se contribuye en la configuración de prácticas masculinas diferentes.

La metodología utilizada en el proyecto se enfocó en realizar intervenciones que permitieran generar insumos para la producción de textos, promoviendo reflexiones sobre las experiencias de varones y la construcción de masculinidades en Medellín. Sobre este aspecto González comenta:
Y realmente lo que nos propusimos fue no hacer una investigación, no nos interesaba hacer una investigación sino abrir una pregunta, una pregunta extendida porque no

\footnotetext{
${ }^{8}$ Información obtenida de la base de datos que manejó el proyecto desde la cual se pudo contar con el registro de la cantidad de participantes.
} 
nos interesaba generar una hipótesis solamente o construir una tesis o nada por el estilo, sino abrir la pregunta para que los hombres se preguntaran por isu condición!, ¿qué es ese proyecto patriarcal que los invalida frente a tantas cosas en la vida? [...] entonces la idea desde el museo Casa de la Memoria era más abrir una reflexión que le sirviera a la sociedad (González, 2016).

La metodología estuvo enmarcada en una investigación de acción participativa que al mismo tiempo desarrollara procesos de sensibilización con diversos varones y mujeres de la ciudad.

\section{La apuesta a una investigación-acción-participativa}

Pensar en una investigación que contribuyera a procesos de transformación de prácticas masculinas hegemónicas fue la apuesta que decidió emprender en el año 2014, el equipo de trabajo del Museo Casa de Memoria, acogiendo como metodología la investigación-acción participativa, no sólo como un trabajo académico, sino que incluyera acciones puntuales de sensibilización.

Se planteó como un proyecto de investigación con una acción transformadora. Era como reflexionar y básicamente aprender qué pasaba con esos modelos de masculinidad dominantes y sí tenían alguna relación, cómo estaban relacionados con la violencia que se había vivido en Medellín. Vos sabés que el conflicto en Medellín y en Antioquia ha tenido digamos una máxima expresión en complejidad, en modalidades, en víctimas, en agresores, en todo tenemos como premio (Londoño, 2016).

La pregunta transversal de este proceso planteaba la relación que existe entre la configuración de masculinidades y la guerra. La construcción de masculinidades en la ciudad y el país está muy atravesada por el conflicto, los varones han desempeñado unos roles que desde la perspectiva de género se han abordado muy poco. El proyecto del Museo Casa de la 
Memoria fue de las primeras intervenciones a nivel nacional que hizo una exploración de cómo los hombres en nuestros contextos reciben una educación para enfrentar los conflictos desde las armas y las vías de hecho.

La perspectiva de género en este sentido cobra relevancia pues es una categoría que acogieron en el proyecto y desde la que se podía visualizar como los varones habían sido educados para la guerra, cómo las instituciones castrenses tienen una gran importancia al momento de construir masculinidades en el contexto de la ciudad y el país, pues resulta ser una forma corrientemente aceptada de cómo los varones pueden demostrar su virilidad. Esta metodología fuera de explorar estas construcciones, también fue un instrumento para generar insumos académicos que permitieran contar con mayores reflexiones sobre el tema.

[...] la metodología del proyecto es investigación acción participativa, o sea, la idea era tener como una intervención en la que los hombres se cuestionaran, en la que se generaran reflexiones al respecto de cómo ha sido esa masculinidad hegemónica, cuáles han sido las masculinidades alternativas pero también era un asunto de investigación porque todos los encuentros se sistematizaban. Cuando había encuentros con hombres siempre había que sacar un análisis al respecto (MAZO, 2016).

El proyecto se formuló desde una perspectiva donde todas/os las/os participantes pudieran expresarse, la metodología investigación-acción participativa plantea un proceso mucho más incluyente, donde los roles de facilitador/a y estudiantes se desdibuja y todas/os desde sus experiencias de vida comparten sus saberes, a partir de estos se generan nuevos conocimientos y se contribuye en la configuración de prácticas masculinas diferentes.

Porque tampoco era una investigación ni de biblioteca ni de pupitre sino una investigación participativa entonces tenía 
que ser gente [orientador] capaz de asomarse también a ese abismo del otro digo yo. A esa pregunta que el otro no se ha hecho y de hacerlo con sensibilidad y con respeto y con cariño $[. .$.$] no es tan fácil parársele a un pelao { }^{9}$ del colegio de San Ignacio estrato 14 o a un mecánico a preguntarle por su masculinidad en una sociedad de estas donde primero: nadie se lo ha preguntado y segundo: nadie la ha puesto en duda, cierto? (González, 2016).

El trabajo con masculinidades en la ciudad tiene muy pocos espacios desde las instituciones estatales, y es un tema que se viene desarrollando desde hace varias décadas en la ciudad, pero con muy poca incidencia, lo que hace que aún existan muchas prevenciones con respecto al tema y que sea poco conocido por la población.

\section{Herramientas de intervención en el trabajo con varones}

Después de tener una metodología definida y el tipo de acción que se quería realizar viene la pregunta sobre los temas a abordar, pues si bien la pregunta por la relación entre la construcción de masculinidades y la guerra es transversal, el proceso tuvo unos tópicos que guiaron el debate, en este sentido uno de los profesionales que participó en el proyecto señala,

Los temas eran: hombres y paz, masculinidad militarizada, masculinidades otras lo llamábamos nosotros que era un espacio donde se hablaba de estos hombres que han tenido unos comportamientos alternativos a la masculinidad hegemónica, museografeándonos era otro, eran cinco talleres en total. Uno era evaluativo, van cuatro...al final se hacía uno de corte evaluativo y de semblanzas que lo llamábamos nosotros (Mazo, 2016).

Durante esos cinco encuentros descritos por Mazo se propició una reflexión sobre cómo es la participación de los

\footnotetext{
${ }^{9}$ En Colombia la palabra "pelao" significa muchacho.
} 
varones en el conflicto de la ciudad y el país, al igual que se trató de propiciar la reflexión sobre contextos en entornos de paz y deconstrucción de masculinidades educadas para la guerra. Una de las estrategias utilizadas por las/os profesionales para trabajar con quienes participaron en el proyecto fue denominado el ritual,

Entonces nosotros sabemos por ejemplo que, contra lo que uno se podría imaginar en principio, en hombres es muy importante el tema ritual. Eso nos ha dado mucho resultado, a los hombres les gusta mucho [...] eso ha sido una sorpresa y uno no creería pues porque como somos tan machos, pero sí! a los hombres nos gusta mucho llegar a un espacio y encontrarlo organizado, con flores, con mándalas, con aromas, eso ha sido muy bien acogido desde los soldados hasta los mecánicos, los pelados [muchachos] de San Ignacio [...]. Eso ha sido una cosa como llamativa, el tema ritual, el asunto del cuerpo es un asunto que es delicado de trabajar en las masculinidades en el sentido en que los hombres tenemos mucho miedo al contacto con otros hombres pero sí se puede trabajar mucho desde la consciencia corporal, desde el juego. El asunto del tema de lo plástico, de poder plasmar y representar a partir no solo de la palabra sino del color, de las texturas, el collage. El asunto de las medicinas ancestrales, la utilización por ejemplo del ambil que es el tabaco no para fumar sino como una pasta que usan los pueblos ancestrales para la conversación, al mambe ${ }^{10}$, las piedras, los aromas, los aceites, el masaje [...] lo que hemos visto es que cuando se logra crear un espacio de confianza entre hombres y se supera como ese asunto de la máscara de quién es aquí [...] (Ossa, 2016).

${ }^{10}$ El mambe es producto de la combinación de hoja de coca con cenizas de yarumo usadas para rituales religiosos por algunas comunidades indígenas de la Amazonía. Para ampliar la información visitar: https:/laparada.uniandes.edu.co/index.php/la-revista/la-revista-1/la-plaza/sobreel-mambe Acceso: 12 noviembre 2020. 
Las experiencias que tuvieron en otras intervenciones con varones y los conocimientos adquiridos les permitieron en este caso identificar el ritual como una forma asertiva para el trabajo con hombres y también como instrumento para romper barreras de acercamiento, pues parte de esas configuraciones masculinas están enmarcadas en el rechazo a expresiones corporales y emocionales asociadas a lo femenino.

Como ya fuera mencionado, el proyecto tuvo dos fases, la primera se ejecutó entre finales del 2014 y principios del 2015 y la segunda y última, entre abril y diciembre del mismo año. Había una tercera fase planeada para el 2016, pero por el cambio administrativo del Museo no se llevó a cabo, puesto que el proyecto se anuló,

En la primera fase se hicieron talleres como herramienta de dialogo con los participantes y de recolección de información [...]. En la segunda fase lo llamamos sentípensantes haciendo alusión como a vincular cuerpo a vincular sentimiento, emoción porque sí creemos y eso sale también de lo que se trabajó con los grupos, que ese exceso de racionalidad que se fomenta en esas identidades masculinas, en esas figuras masculinas, impide el acercamiento [...]. Se hacían disco foros, se hacía sensibilización con esencias, con mambe y se hacía discusión. Entonces se hicieron talleres con los grupos, con cada grupo se hacían cinco talleres con unos temas que aunque eran distintos conservaban el eje de la pregunta: ¿qué tiene que ver esto, nuestra manera de haber sido educados como hombres con la guerra? (Londoño, 2016).

Las masculinidades se configuran desde cimientos muy racionales donde asuntos como el sentir, las expresiones corporales que enuncian emociones de debilidad, llanto, tristeza, cariño, son descalificados como características de feminidad. Uno de los elementos centrales desde los que se configuran las masculinidades es a través del cuerpo, pues es el dispositivo del que dispone el patriarcado para adoctrinar a los varones. 
Algunas reflexiones en la construcción de masculinidades en la ciudad

La pregunta que hizo el proyecto en referencia a la construcción de masculinidades y su relación con los fenómenos de guerra en Medellín, dio pie a unas reflexiones acerca de la configuración de masculinidades en el país proclives al establecimiento de conflictos que vale la pena resaltar en este texto.

¿Por qué los hombres van a la guerra? Los hombres van a la guerra por una decisión patriarcal que es que cumplen un servicio civil obligatorio o que uno de sus oficios es ser soldados de la guerra desde todos los imaginarios que le crean desde chiquitos pero también porque es una salida a su hombría, porque es una salida a ese modelo patriarcal del macho teso [fuerte] armado, entonces por eso son los sicarios y por eso son los milicianos de tantas guerras [...] el no lugar, el no tener empleo, el no tener educación, el no tener oportunidades lleva a los chicos a la guerra. Pero la guerra también como una salida deseada en el sentido en el que te da un lugar, un lugar de poder. Es mucho más honroso ser un sicario, es mucho más honroso ser el jefe del combo [grupo armado ilegal] que vender galletas en una esquina por ejemplo. En ese modelo patriarcal pasa una chica por su casa y usted no es nadie y entonces esa chica le dice a usted: ¿usted qué hace? Y usted le dice: yo vendo frunas [caramelos] en un bus [...] no! usted prefiere decir que es el malo de la cuadra y esa chica quedó prendada (González, 2016).

La participación en grupos armados les da a algunos hombres prestigio social y poder dentro de la ciudad, lo que también los hace estar en unas jerarquías más altas en los círculos de varones con los que se relacionan, generando temor en las comunidades que habitan. Para el caso puntual de Medellín, la falta de control estatal ha hecho que estas estructuras ilegales se conviertan en las autoridades de los barrios más pobres de la ciudad. Así como para Colombia como un todo, la valorización 
social de esta "cultura de la violencia", la naturalización de la misma durante todos estos años, unida a la raíz y estructura "machista" que las sociedades latinoamericanas heredaron y conformaron históricamente, hace más complejo y difícil el tema.

Las estructuras económicas y sociales tienen grandes incidencias en la participación de los varones en la guerra, aunque ya desde la configuración de masculinidades en niños y jóvenes se dan unos antecedentes que los hacen propensos a participar en la guerra, pues tal como lo expone Ossa en la publicación que se realizó de la primera fase del proyecto,

En muchos lugares de la ciudad y no solo en los estratos más bajos, los pillos [nombre que se le da en el contexto antioqueño a los hombres que participan en grupos armados ilegales sobre todo en aéreas urbanas] son referentes cotidianos de masculinidad que encarnan unos atributos deseables para los niños y adolescentes, quienes son atraídos por sus prácticas transgresoras asociadas a la adrenalina, a la aventura, a la seducción; así como por sus objetos de poder, materializados en la moto, el arma y la ropa de marca (Ossa, 2015:30).

La incidencia que tiene la configuración de masculinidades en estos fenómenos de guerra ha sido poco estudiada, el proyecto del Museo resulta pionero en este sentido ${ }^{11}$, siendo la primera institución del país en hacer un trabajo con varones en la desarticulación de prácticas masculinas que desde lo cultural, político y simbólico mantienen latentes dinámicas de guerra. En el contexto actual de la ciudad y del país es fundamental diseñar estrategias para modificar estas prácticas, las cuales son una forma corrientemente aceptada de ser hombres, y en algunos casos significa prestigio y poder.

\footnotetext{
${ }^{11}$ En las entrevistas que se realizaron al equipo que conformó el Museo Casa de la Memoria para este proyecto, ninguna/o de los entrevistadas/os tuvo conocimiento de otra intervención similar en el país, tampoco se encontraron referencias semejantes en la revisión bibliográfica realizada.
} 
Es un tema urgente para una sociedad que lleva décadas, por no decir siglos, atrapada en un círculo interminable de violencias y guerra y donde los varones jugamos un papel protagónico en la postergación de esas violencias. Yo creo que no sólo como conversación sino desde escenarios estéticos, simbólicos... desde muchos escenarios es urgente empezar a movilizar esa sensibilización en los hombres porque tras de esas prácticas de riesgo y de agresión hay un tema de salud pública enorme, las estadísticas en eso son abrumadoras. Las de medicina legal, el porcentaje de muertes de los hombres por temas de autoagresión y de agresión a otros es como de un $90 \%$ en comparación a las mujeres entonces eso es algo que es definitivo que hay que abordar (Osorio, 2016).

En este sentido resultan fundamentales propuestas como la del Museo Casa de la Memoria, que trabajaron con hombres de diferentes procedencias, al igual que las investigaciones en la académica que permitan conocer más la problemática desde esta perspectiva, y los procesos de evaluación de estos proyectos también resultan de gran relevancia para mejorar las técnicas desde las que se realizan estas intervenciones.

\section{Algunas reflexiones a modo de conclusión}

La política pública de Sana Convivencia y Atención Moral y Material a las víctimas de los conflictos armados, fue el marco institucional a través del cual se dio surgimiento al Museo Casa de la Memoria, que fue inaugurado en el año 2013. Esta institución ejecutó un proyecto "Género, Memoria y Despatriarcalización" entre el segundo semestre de 2014 y diciembre de 2015 en el cual se hizo una exploración por la configuración de masculinidades y su relación con la guerra.

El estudio sobre masculinidades es algo que se viene desarrollando en la ciudad desde las primeras décadas del siglo $\mathrm{XXI}$, en un proceso que ha fusionado procesos académicos $e$ intervenciones puntuales con hombres en perspectiva de género. Estas intervenciones si bien existen, no están atadas a ninguna 
política pública de género, sino que se han dado de acuerdo a los intereses y grado de sensibilización de las/os funcionarias/os que se acercan a estos temas. Para que el asunto de masculinidades tenga mayores impactos y se pueda generar una reflexión mayor, a nivel de la ciudad y por qué no del país, es necesario que este no dependa de los intereses de las/os funcionaria/os de turno, sino que esté integrada dentro de las políticas públicas de género y del gobierno. Por esta razón la evaluación de las propuestas innovadoras en este tema, como lo fue el proyecto que motivó este estudio es de gran importancia para observar y comprender la importancia social del tema $e$ ir construyendo reflexión en esta dirección a partir de lo ya implementado por una institución pública que está en consonancia con el proceso de pacificación que el país como un todo se ha propuesto, y con los avatares que esto ha generado.

El Museo Casa de La Memoria entre los años 2014 y 2015 logró identificar un problema en la ciudad en relación a la incidencia que tiene la participación masculina en los fenómenos de guerra que se han presentado históricamente en la ciudad y el país, los cuales tienen altos costos económicos, sociales y culturales. Académicamente todavía está pendiente una investigación que indague más profundamente sobre los costos que tienen estas configuraciones masculinas en la sociedad, pues aún no se logra determinar cuánto dinero invierte el Estado en cárceles, en la guerra, en accidentes de tránsito, que son mayoritariamente masculinos (Ossa, 2015).

Colombia aún no ha podido determinar cuantitativamente cuál ha sido la participación de los hombres en la guerra, pues parece demasiado evidente cuál ha sido su cuota de contribución, pero aún no se ha indagado lo suficiente por las construcciones culturales, económicas e históricas que hay atrás de este proceso.

El proyecto que ejecutó el Museo fue un primer acercamiento a esta situación. En Colombia, cuando se ha incluido la perspectiva de género en temas de conflicto se ha focalizado los estudios, consecuencias e impacto en las mujeres (en muchos casos desde su condición de víctimas de esos procesos 
de violencia), y se ha dejado un poco de lado lo que ha sucedido con los hombres. En un momento, en el que se están elaborando propuestas para construcción de la paz, resulta fundamental generar intervenciones y producciones académicas donde se analice este fenómeno. Asimismo, es de suma importancia que estas reflexiones académicas $e$ intervenciones y experiencias puntuales, puedan tener continuidad en las políticas públicas de memoria y género propuestas, de manera que aborden este tema complejo integralmente para que la deconstrucción de modelos patriarcales y masculinidades hegemónicas arraigadas en la sociedad pueda ser más efectiva y duradera.

\section{Referencias bibliográficas}

BEDOYA, Pablo. ¿Los espacios de memoria, ni de víctimas ni de victimarios? Bogotá, 2016 [http://elfichero.com/los-espacios-dememoria-ni-de-victimas-ni-de-victimarios/ - acceso: 30 enero 2016].

CENTRO NACIONAL DE MEMORIA HISTÓRICA. Aniquilar la Diferencia. Lesbianas, gays, bisexuales y transgeneristas en el marco del conflicto armado colombiano. Bogotá, CNMH - UARIV - USAID OIM, 2015.

CENTRO NACIONAL DE MEMORIA HISTÓRICA. La guerra inscrita en el cuerpo. Informe nacional de violencia sexual en el conflicto armado. Bogotá, CNMH, 2017a.

CENTRO NACIONAL DE MEMORIA HISTÓRICA. Medellín: memorias de una guerra urbana, CNMH. Bogotá. Corporación Región Ministerio del Interior - Alcaldía de Medellín- Universidad EafitUniversidad de Antioquia. 2017b.

COLMENARES, Ana Mercedes. Investigación-acción participativa: una metodología integradora del conocimiento y la acción. Voces y Silencios: Revista Latinoamericana de Educación, vol. 3, n. 1, Colombia, Universidad de los Andes, 2011, pp.102-115.

CONCEJO DE MEDELLÍN. Acuerdo Municipal número 45 de 2006.

ESQUIVEL VENTURA, Isabella. Análisis de las políticas públicas de acceso a las mujeres a una vida libre de violencia en el Distrito 
Federal: propuesta de intervención para el trabajo con varones y la prevención de la violencia masculina. Disertación de Maestría en Políticas Públicas y Género, Ciudad de México, Flacso México, 2014.

FAUR, Leonor. Masculinidades y desarrollo Social. Las relaciones de género desde la perspectiva de los hombres. Bogotá, UNICEF, 2004.

FERNÁNDEZ DE AVLÉS, Bakea Alonso. Trabajo social y perspectiva de género: los hombres como "colectivo" de intervención. In: CARBONERO, D; RAYA, E.; CAPARROS, N. y GIMENO, C. (coords). Respuestas transdisciplinares en una sociedad global. Aportaciones desde el trabajo social. Logroño, Universidad de La Rioja, 2016, pp.1-23.

GARCÍA, Leonardo Fabian. Nuevas masculinidades: discursos y prácticas de resistencia al patriarcado. Disertación de maestría en Ciencias Sociales con mención en Género y Desarrollo, FLACSO Ecuador, 2013.

GARDA, Roberto. Experiencia de trabajo con varones como una estrategia de prevención de la violencia -Caso hombres por la equidad, México. En: Seminario Internacional. Masculinidades y Políticas Públicas. Varones en la Prevención de la Violencia de Género. Perú, UNFPA. 2014.

GRUPO DE MEMORIA HISTÓRICA. iBasta ya! Colombia: Memorias de guerra y dignidad. Bogotá, Imprenta Nacional, 2013.

INSTITUTO NACIONAL DE MEDICINA LEGAL Y CIENCIAS FORENSES. Forensis 2014, datos para la vida. Bogotá, Instituto Nacional de Medicina Legal y Ciencias Forenses, 2014.

MEDINA ARBELÁEZ, Camila. No porque seas paraco o seas guerrillero tienes que ser un animal: Procesos de socialización en FARC-EP, ELN y grupos paramilitares (1996-2006). Bogotá, Ediciones Uniandes, 2008.

MEDELLÍN COMO VAMOS - SEGURIDAD CIUDADANA. Medellín, 2014. [http://www.medellincomovamos.org/seguridad-y-convivencia acceso: 11 mayo 2015].

MEDELLÍN un Hogar para la Vida, Plan de Desarrollo 2012-2015 (2011)

[https://www.medellin.gov.co/irj/go/km/docs/wpccontent/Sites/Subport 
al\%20del\%20Ciudadano/Plan\%20de\%20Desarrollo/Secciones/Public aciones/Documentos/PlaDesarrollo2012-2015/2012-0430 Proyecto\%20de\%20acuerdo\%20VERSION\%20COMPLETA.pdf acceso: 11 mayo 2015].

MENJIVAR OCHOA, Mauricio (edit.). ¿Masculinidades Tránsfugas? Políticas Públicas y experiencia de trabajo sobre masculinidad en Iberoamérica, Costa Rica, Flacso Costa Rica, 2012.

MUÑOZ-ONOFRE, Darío. Masculinidades bélicas como tecnología de gobierno en Colombia. La manzana, vol.5, n. 5, Universidad Autónoma de Puebla, diciembre 2011, pp.96-107.

MUSEO CASA DE LA MEMORIA. Informe 2013-2014. Medellín, 2014.

OSSA, Carlos Alberto. Diálogos sentipensantes sobre Patriarcado, Masculinidades y guerra en Medellín. Trayectorias analíticas y poéticas, Medellín. Museo Casa de la Memoria, 2015.

PIZARRO LEONGÓMEZ, Eduardo. Una lectura múltiple y pluralista de la historia. En: Comisión Histórica del conflicto y sus víctimas. Bogotá, Ediciones desde Abajo, 2015, pp.45-46.

PRESIDENCIA DE LA REPÚBLICA DE COLOMBIA. Lineamientos de la Política Pública Nacional de Equidad de Género para las Mujeres, Bogotá, 2012.

RICO, Nieves "Cambios de Gobierno y sostenibilidad de las oficinas de la mujer". Colombia, 2005 [https://www.cepal.org/mujer/proyectos/gobernabilidad/documentos/re union/NRico.pdf - acceso: 30 de marzo de 2016].

THEIDON, Kimberly. Reconstrucción de la masculinidad y reintegración de excombatientes en Colombia. Fundación ideas para la paz. Bogotá, 2009 [http://www.bivipas.unal.edu.co/bitstream/10720/642/1/266theidon\%2C\%20kimberly.pdf - Acceso: 3 de marzo de 2020].

VIVEROS VIGOYA, Mara. De quebradores y cumplidores: Sobre hombres, masculinidades y relaciones de género en Colombia. Universidad Nacional de Colombia, Bogotá, 2002. 


\section{Entrevistas}

GONZÁlEZ, Lucía. Entrevista concedida a Daniel Arias Osorio, el 9 de julio de 2016.

LONDOÑO, Luz María. Entrevista concedida a Daniel Arias Osorio el 9 de julio de 2016.

MAZO, Andrés. Entrevista concedida a Daniel Arias Osorio el 9 de julio de 2016.

OsoRIO, Jaime Alberto. Entrevista concedida a Daniel Arias Osorio el 9 de julio de 2016. Psicólogo experto en intervención con varones 